\title{
III. DOCUMENTO
}

\section{RAFAEL GUTIÉRREZ GIRARDOT EN LA REVISTA QUIMERA (1981-2003) \\ UNA ANTOLOGÍA EJEMPLAR}

\author{
Carlos Rivas \\ Universidad de Salamanca \\ crivaspolo@yahoo.es
}

Palabras clave: Rafael Gutiérrez Girardot, revista Quimera, literatura y crítica latinoamericana.

KEY WORDS: Rafael Gutiérrez Girardot, Quimera Review, Latin-American literature and criticism.

La larga vinculación del ensayista Rafael Gutiérrez Girardot (1928-2005) con la revista Quimera comienza en 1981 (cuatro meses después del nacimiento de esta publicación, en noviembre de 1980) y termina en 2003, dos años antes de la muerte del crítico colombiano. Un lapso de 22 años que coincide con su período de plenitud creativa y durante los cuales aparecen 28 artículos cuya calidad y diversidad temática configuran una muestra ejemplar de su obra ensayística. Con relación a este decisivo período, anotemos que la aparición de la revista coincide con los años en que Gutiérrez Girardot se encuentra trabajando en la que sería la expresión más acabada de su trabajo intelectual: el libro Modernismo (1983), texto fundamental de la crítica hispanoamericana del siglo XX. Un testimonio de estos trabajos previos puede leerse en la carta enviada al ensayista por Ángel Rama, ocho meses antes del lanzamiento de la revista: "Mi querido Rafael: me interesó mucho de tu carta la noticia de que estás trabajando sobre un tema de Modernismo, vinculando el hispanoamericano con el catalán, cosa que si no me acuerdo mal también hace Darío en su España contemporánea" (Washington, 25.3.80) ${ }^{1}$. Meses antes de la aparición de

${ }^{1}$ La correspondencia utilizada en este trabajo ha sido suministrada por la Dra. Bettina Gutiérrez Girardot, hija del escritor, quien generosamente ha cedido a su autor éste y otros documentos epistolares como parte del material bibliográfico con el que actualmente realiza, en la Universidad de Salamanca, su doctorado sobre el ensayista colombiano. Los datos de las cartas (Ciudad, día.mes.año) al final de cada cita, entre paréntesis en el texto. 
Modernismo, el propio Gutiérrez Girardot envía a la revista Quimera un anticipo del libro, el artículo-reseña titulado "El Modernismo incógnito" (Q27)², a propósito del cual le escribe Gonzalo Sobejano: "Querido Rafael: [...] He leído tu ensayo sobre el Modernismo en Quimera, lleno de justicia y de ánimo, que es lo que le falta a la crítica al menos en España, desde que desapareció Clarín. Imagino que sea una primicia del libro, ya en prensa, que espero con máximo interés" (s/c, 2.4.83).

Sirva la mención de Ángel Rama a Rubén Darío y su vinculación con el Modernismo español para introducir unas breves palabras sobre la temprana relación de Gutiérrez Girardot con España, país al que viaja en 1950 (22 años) con el fin de proseguir sus estudios, iniciados en Colombia. Este período de formación europea, que comienza en España (1950-1953) y concluye seis años después en Alemania (1953-1956) ${ }^{3}$, va a favorecer la consolidación de su arraigo a la propia tradición - ejemplarizada en las figuras de José Ortega y Gasset y Alfonso Reyes- entrañable vinculación que se constituye a su vez en uno de los fundamentos de su apropiación del legado europeo. Desde este punto de vista, el iniciático viaje del joven colombiano no hacía otra cosa que seguir el camino trazado por el propio Darío, experiencia fundacional que bien puede equipararse a la posterior vivencia española de Alfonso Reyes, quien bajo otro contexto -el del período de la restauración borbónica, de la Junta de Ampliación de Estudios, de la Residencia de Estudiantes- permanecerá 10 años en Madrid (1914-1924) vinculado a lo mejor de la vida intelectual. Relación que nos permite señalar, en términos muy generales, una común experiencia madrileña (y europea) que posibilitó a la inteligencia americana tanto la afirmación de su conciencia americoespañola, como el despliegue de los postulados cosmopolitas implícitos en el horizonte modernista legado por Rubén Darío, presupuestos que como señala el mismo Reyes, nos llevarían a "buscar nuestros instrumentos culturales en los grandes centros europeos, acostumbrándonos así a manejar las nociones extranjeras como si fueran cosa propia” (Reyes 233). Simbólicamente expresada por Darío en las

2 Todas las referencias de Gutiérrez Girardot en la revista Quimera llevan esta nomenclatura entre paréntesis en el texto: $\mathrm{Q}+$ número de ejemplar: páginas. No incluidas en la Bibliografía, las referencias completas ("Título del artículo". Ejemplar (año): páginas) de los 28 artículos publicados puede consultarse en el Anexo 1: Rafael Gutiérrez Girardot en Quimera (listado cronológico).

${ }^{3}$ Rafael Gutiérrez Girardot llega a España gracias a una beca del Instituto de Cultura Hispánica. Realiza estudios de filosofía con Xavier Zubiri y de sociología en el Instituto de Estudios Políticos de Madrid. Entre otras actividades, participa en las Primeras Jornadas de Lengua y Literatura de Salamanca (1953) y en los cursos de verano (1951 y 1952) de la Universidad Internacional Menéndez Pelayo (Santander), donde conoce al librero español Francisco Pérez González, con quien funda la editorial Taurus. En Friburgo (República Federal Alemana), asiste a los seminarios de filosofía de Heidegger y realiza el doctorado de romanística bajo de dirección de Hugo Friedrich, con una tesis sobre Antonio Machado. Alemania se convierte desde entonces en su residencia definitiva. Entre 1970 y 1993 ejerce como profesor titular de hispanística de la Universidad de Bonn, ciudad en la que fallece en el año 2005. 
"Palabras preliminares" de sus Prosas profanas (1896): “Abuelo, preciso es decíroslo: mi esposa es de mi tierra, mi querida de París", esta experiencia europea no solo dejaba trazado el camino hacia la conquista de nuestra expresión; también conllevaba, como anota Gutiérrez Girardot a propósito de la originalidad latinoamericana, un ineludible mandato de rigor intelectual: "la asimilación crítica de la cultura europea, que supone a la vez un arraigamiento en la propia. Pues sin éste no es posible asimilar, sino solo imitar. Y sin este arraigamiento, la asimilación no puede ser crítica ni creadora" ("Prólogo", XVII).

De esta experiencia formativa emprendida por Gutiérrez Girardot queda un temprano y prometedor testimonio: los trabajos escritos por el joven estudiante para diversas publicaciones de Colombia y España ${ }^{4}$, entre las que destaca la revista Cuadernos Hispanoamericanos, publicación insignia del Instituto de Cultura Hispánica, creada en 1948 con la intención de convertirse en una ventana abierta hacia Hispanoamérica. Desde un punto de vista meramente cuantitativo, resulta significativo comprobar que si se exceptúa esta revista -donde Gutiérrez Girardot publicó un total de cincuenta y cuatro artículos, cuarenta y uno de los cuales aparecieron durante los seis años de su período de formación (un promedio de siete artículos por año)-, será en Quimera donde se encuentra el mayor número de textos aparecidos en una misma publicación: veintiocho en un lapso de veintidós años.

La comparación no solo obedece al hecho de que ambas revistas sean españolas: nacidas en dos contextos históricos tan diferentes -Cuadernos Hispanoamericanos en los años de la inmediata posguerra, del unánime rechazo de la comunidad internacional a la dictadura; Quimera en los años siguientes al final del largo período franquista-, la comparación pretende señalar las diversas manifestaciones de una misma voluntad por fortalecer, más allá de sus intenciones políticas, el diálogo cultural con el ámbito hispanoamericano y la decidida voluntad de Gutiérrez Girardot por participar en las convocatorias abiertas por ambas coyunturas.

En su contexto adecuado, esto es, en el horizonte de la crítica literaria en Hispanoamérica durante la segunda mitad del siglo XX, el alcance y significado de ambas participaciones puede ponerse en relación con los títulos -solo con los títulos- de dos obras que en la primera mitad de este siglo ofrecieron una interpretación nueva de nuestro continente: los iluminadores y certeros Seis ensayos en busca de nuestra expresión (1928) de Pedro Henríquez Ureña, y aunque solo referidos al Perú, pero igualmente suscitadores para Latinoamérica, los Siete ensayos de interpretación de la realidad peruana (1928) de José Carlos Mariátegui. Como lo indican sus títulos, eran "ensayos" no solamente por la forma literaria, sino por el propósito de explorar y de indicar los primeros caminos seguros

${ }^{4}$ Mencionemos solo tres: en Colombia, la revista Mito (1955-1962), considerada el "inicio" de la modernidad en Colombia, en cuya gestación participaría Gutiérrez Girardot; en España, Correo literario (1950-1954), revista del Instituto de Cultura Hispánica, dirigida por Leopoldo Panero y la revista Índice: "interesante experiencia con reminiscencias falangistas y criterios netamente progresistas, surgió, dirigida por Juan Fernández Figueroa, en 1949” (Mainer 62). 
hacia ella. En estrecha relación con el campo semántico implícito en la promesa de lo "ensayístico", la analogía con los títulos de estas dos obras nos permite establecer una comparación entre los materiales publicados por Gutiérrez Girardot en ambas revistas: así, mientras sus tempranos artículos en Cuadernos hispanoamericanos pueden leerse como "ensayos en busca" o de "interpretación"-publicado en estas fechas, su libro Jorge Luis Borges (1959) se subtitula Ensayo de interpretación-, los de Quimera, si bien es cierto que también pueden considerarse ensayos en el sentido de exploración y del estilo literario, no son ya "ensayos en busca" o "de interpretación": escritos tres décadas más tarde, comenzaron a presentar los resultados de esa búsqueda, el descubrimiento de nuevas vetas. La más lúcida y acabada expresión de estos hallazgos, el libro Modernismo, demostró no solo el nivel alcanzado por el crítico colombiano; también la posibilidad de convertir en praxis la frase de Jorge Luis Borges (1932): "creo que nuestra tradición es toda la cultura occidental, y creo también que tenemos derecho a esta tradición” (272).

Antes de pasar a considerar los trabajos de Gutiérrez Girardot en Quimera, quisiéramos citar, a modo de paradigmática ilustración sobre su período de formación, una hermosa metáfora extraída de su primer libro, La imagen de América en Alfonso Reyes (1955): "Conocedor de la empresa en que se ha empeñado [Reyes] sigue la ruta de Colón, la de los presagios y las adivinaciones. Su esfuerzo tiene los mismos premios que la aventura del descubridor: la visión de la tierra firme y su incorporación a la Historia Universal" (16). Que el apelativo metafórico de explorador aventurero puede aplicarse a Gutiérrez Girardot, queda demostrado en la carta que este envía a Reyes, a raíz de la publicación en Cuadernos Hispanoamericanos de su artículo "La utopía americana de Alfonso Reyes" (1952), germen del citado libro:

\begin{abstract}
Admirable Don Alfonso: [...] La nota tiene pocas o ninguna pretensiones. Quería yo que con ella, los muchos que no saben que América existe como problema, acudieran a sus libros en busca de orientación y consejo. Hubiera querido hacer algo más completo, más detallado, más redondo, pero no me fue posible. Porque precisamente yo fui uno de esos que no saben que existe América. Sólo cuando llegué a España me di cuenta de la cuestión, y fue entonces cuando "descubrí" un buen número de autores que ya desde hace muchísimo tiempo se habían ocupado del asunto. Es terrible. Por que yo en Colombia no me ocupaba ni siquiera de comprar libros hispanoamericanos sobre cuestiones nuestras, pues ni miraba los libros. Esta sería una muestra de nuestra incomunicación. Y como esta hay miles y miles (Madrid, 17.1.52).
\end{abstract}

Si es cierto que "la historia de un escritor", como dice Roland Barthes, "es la historia de un tema y sus variaciones", puede decirse -ampliando la frase al crítico y al ensayista-, que la historia de Gutiérrez Girardot es la historia de los variados asedios acometidos con el fin de ubicar el "tema" hispanoamericano tanto en su ámbito propio como en relación con el contexto europeo. La tarea "pedagógica" implícita en estos asedios -Insistencias, Provocaciones, Aproximaciones son los títulos de algunas de sus antologías de ensayosqueda manifiesta en una entrevista a Gutiérrez Girardot a raíz de la publicación de su libro Horas de estudio (1976), primera de las antología hecha por el propio ensayista: “Todos mis trabajos responden a una preocupación: la de transmitir a mis compatriotas lo que he 
conocido en Europa. Y la de demostrar de una manera accesible -y por eso periodística ${ }^{5}$ que un latinoamericano no es menos que un europeo" ("Respuestas" 7). Y si bien este propósito va a orientar el conjunto de la obra ensayística de Gutiérrez Girardot, veamos ahora brevemente cómo las circunstancias que propiciaron la aparición de una revista como Quimera, hicieron de esta publicación el espacio justamente adecuado para que el maduro ensayista dejara entre sus páginas el que quizá sea el mejor conjunto antológico para conocer y evaluar los resultados de sus búsquedas y descubrimientos.

El primer número de la revista Quimera apareció en la ciudad de Barcelona, en noviembre de 1980. Su fundador, Miguel Riera Montesinos, por aquel entonces codirector de El Viejo Topo (fundada en octubre de 1976, un año después de la muerte de Franco), dejaba esta mítica publicación para fundar otro tipo de revista. Preocupado por unos esquemas que "correspondían un poco al periodo anterior, al período de Franco" y por el inmenso "agujero" dejado en el aspecto cultural, propone a sus compañeros "hacer una revista y una editorial literaria ${ }^{6}$ y trabajar en el campo de la cultura. Esa propuesta no fue aceptada y entonces hablé con otras personas y empecé la aventura de Quimera" (Riera, "Quimeras" 9).

En oposición al panorama esencialmente político que los fundadores imprimieron a $E l$ Viejo Topo-si bien lo "político", como lo expresa el mismo Riera, era un "concepto tan amplio que casi cualquier cosa, incluyendo [...] la música, el psicoanálisis y a las artes plásticas, tenían cabida en él” ("El viejo" 3)-, Quimera presentaba una línea editorial más acorde con la nueva situación cultural. Su subtítulo, "Revista de literatura", revelaba el propósito de enfrentar 40 años de censuras e incomunicaciones ejercidas por la dictadura, muchas de las cuales, "obedecían a problemas editoriales, a problemas de derechos: muchos títulos no habían aparecido en España no por razones de censura, sino porque los derechos los tenían editoriales latinoamericanas que no tenían difusión en España, y otros estrictamente por problemas de censura (Riera, "Quimeras" 12). Se buscaba, en último término, ampliar el panorama cultural haciendo de la lengua española una patria común y de la revista un puente con la cultura y la literatura latinoamericana, sin olvidar, por supuesto, la europea y la norteamericana.

${ }^{5}$ Esta positiva referencia al periodismo debe entenderse como provocador desafío de Gutiérrez Girardot "a la excesiva profesionalización puramente formal (en los historiadores nuevos y sociólogos) que está creando un nuevo "academicismo" con el peligro de todo academicismo, esto es, el del temprano anquilosamiento y el de un arrogante dogmatismo" ("Respuestas" 9), olvidando el papel "misionario" jugado por el intelectual en el proceso de construcción de las naciones hispanoamericanas, tradición que Gutiérrez Girardot hará suya y sobre la cual edificará el impulso pedagógico o constructivo que anima toda su obra: "Cuando yo digo que tenemos una rica tradición del siglo XIX con Bello, Sarmiento, Montalvo, etc., estoy hablando de una tradición que ha sabido enfrentarse a una tradición europea, asimilarla y darle, como dice él [Bello] estampa nacional. Yo me considero seguidor de esa tradición" ("El desmitificador" 4).

${ }^{6}$ La Editorial Montesinos, fundada en 1980. 
Basta echar una ojeada al primer número de Quimera para comprobar una nómina de autores que bien podían representar a cabalidad los propósitos señalados. Encabezado por un poema/editorial de Octavio Paz, aparecieron artículos de Juan Goytisolo, Susan Sontag, José María Valverde, Jorge Semprún, Manuel Puig, algunos textos de Gombrowicz y Faulkner, así como una entrevista de Cristina Peri Rossi a Juan José Arreola. Por lo demás, el número inaugural dejaba expuestas las que serían las características de la revista a lo largo de sus años: independencia, actualidad (aunque sin seguir las modas) y una excelente calidad literaria, todo orientado, como señala Miguel Riera, por una concepción "rigurosa", no elitista de la literatura.

\section{TRES APROXIMACIONES}

La noción de "antología ejemplar" que da subtítulo a este trabajo no solo se refiere a los ensayos aparecidos en Quimera como una muestra ejemplar del conjunto de la labor intelectual del crítico colombiano, también debe esta denominación a una elemental comprobación: algo más del sesenta por ciento de los veintiocho artículos publicados en la revista aparecen (algunos dos veces) en ocho de las catorce antologías de Gutiérrez Girardot editadas hasta la fecha ${ }^{7}$.

Esta comprobación (que hace del conjunto publicado en Quimera una "antología de antologías") resultará decisiva a la hora de articular este abundante material, toda vez que nos permite elegir dos de estas colecciones de ensayos -Aproximaciones (1986) y Provocaciones (1997)-, cuyos criterios de selección, trazados por el propio Gutiérrez Girardot, posibilitan el acercamiento y la ilustración de las principales líneas temáticas y conceptuales de su estilo ensayístico, caracterizado por la desenvuelta familiaridad de su trato con los ámbitos culturales de Alemania, España e Hispanoamérica; por la solidez teórica de una obra fundamentada en la literaria, la filosofía, la sociología y la historiografía; por una vocación polémica y peleadora que ha terminado por configurar una de las voces más personales de la crítica en Hispanoamérica.

La articulación del material en torno a estas dos antologías no desvirtúa el objetivo de este trabajo, centrado en el estudio de los ensayos publicados originalmente por Gutiérrez Girardot en la revista Quimera. De hecho, creemos que dicha articulación contribuye a ampliar nuestra comprensión de este corpus ensayístico al ponerlo en estrecha relación con la orgánica unidad que caracteriza el conjunto de la labor intelectual del crítico colombiano. Es lo que justifica nuestras referencias a las advertencias preliminares de ambas antologías. Como sus nombres lo indican, mientras la primera antología contiene diversas aproximaciones a los ámbitos de la historiografía literaria, la sociología y la poesía, la segunda nos proporciona un acercamiento a su señalada vocación de provocador polemista.

7 Véase el Anexo 2: Antologías de Rafael Gutiérrez Girardot (no incluidas en la Bibliografía), donde puede consultarse la lista de los artículos de Quimera publicados en cada una de ellas. 
Publicada en 1986, Aproximaciones es la primera antología en incluir artículos publicados en Quimera. De los diez trabajos que la componen, Gutiérrez Girardot eligió tres de ellos, obedeciendo al criterio de selección declarado en la "Advertencia" (7-10): "Bajo el título de Aproximaciones [...] se recogen en este volumen ensayos sobre historiografía literaria, sobre el Modernismo, sobre dos teóricos de la sociología literaria y sobre dos poetas contemporáneos" (7). Estos ensayos son: "El Modernismo incógnito" (incluido en el capítulo I, dedicado a la historiografía literaria); "Walter Benjamin y sus afinidades electivas" (que con un artículo sobre Georg Lukács conforma el capítulo II, dedicado dos teóricos de la sociología literaria); y "La lucidez histórica de Jorge Guillén" (con Gottfried Benn, los dos poetas contemporáneos que conforman el tercer y último capítulo).

Incluir "El Modernismo incógnito" (Q27) en el capítulo correspondiente a la historiografía literaria significa, como veremos más adelante, incluir la experiencia modernista en un horizonte más amplio que el meramente estético o literario. Anticipo del libro Modernismo, "El Modernismo incógnito" es una apretada exposición del largo proceso histórico que inscribe la experiencia modernista en el horizonte de la sociedad occidental capitalista. Desde esta perspectiva, Modernismo hispanoamericano o "98" español forman para Gutiérrez Girardot aspectos de un mismo fenómeno cuyo particular enfoque temático y metodológico se constituye en la más lúcida y elegante refutación al conjunto de tópicos, fanáticas preeminencias o nacionalismos estériles que han caracterizado la gran mayoría de acercamientos al Modernismo hispanoamericano. La señalada familiaridad de su trato con la cultura occidental permite a nuestro ensayista establecer un fructífero diálogo entre una diversidad de voces que más allá de sus diversos registros, responden a un mismo complejo de supuestos sociales y culturales. De allí sus críticas implacables a las cegueras de la historiografía española pero también de la historiografía hispanoamericana; las precisiones conceptuales que son implícita lección (como el problema del "galicismo mental" achacado a Darío por Juan Valera, entre otras suscitaciones); el mapa teórico que traza un sendero abierto para futuros investigadores y que se constituye en un auténtico "programa" metodológico, expresado en sus análisis sobre la relación de la sociedad burguesa con el artista, sobre las implicaciones sociales de la secularización o sobre los complejos problemas de la vida urbana, entre otras consideraciones.

Exceptuando este artículo, los cuatros ensayos restantes que conforman el primer capítulo de Aproximaciones están dedicados a la contextualización y profundización de los caminos abiertos por la historiografía literaria de Pedro Henríquez Ureña: $1^{\circ}$ ) la "Revisión de la historiografía literaria latinoamericana"; $2^{\circ}$ ) los "problemas" que plantea tanto la "periodización" de esta historia, como $3^{\circ}$ ) los "temas de una historia social"; finalmente, $4^{\circ}$ ) los implícitos desafíos que el trabajo del gran maestro dominicano deja planteados a nuestra historiografía literaria. Escribe Gutiérrez Girardot: "Esta historiografía está animada por un propósito bolivariano y martiano que tiene, consecuentemente, proyecciones políticas, esto es, la de la unidad de Nuestra América como única posibilidad de una emancipación real y de la realización política de Nuestra América como patria de la justicia" (Aproximaciones 7). 
Desde esta perspectiva, "El Modernismo incógnito" aparece como continuación de aquella historiografía literaria, como primera tentativa de respuesta a sus implícitos desafíos, por desgracia hoy completamente olvidados. Lo confirma la continuación de la cita anterior, que bien puede aplicarse a sus consideraciones sobre el Modernismo: "Consiguientemente, esta historiografía y la concepción política que subyace a ella, excluye de por sí los nacionalismos y las diversas variaciones de éste, como el indigenismo, cuyo fantasma se mantiene pertinazmente pese a su repetido fracaso literario" (7).

Desde otra particular problemática -la de la llamada literatura del boom-, el artículo "Los olvidados: América sin realismos mágicos" (Q46-47), también puede leerse como una nueva tentativa de comprensión de dicha literatura a partir de las suscitaciones abiertas por la historiografía de Henríquez Ureña. A través de un procedimiento metodológico que es una muestra aleccionadora de los presupuestos teóricos que sustentan su modalidad crítica, el ensayista colombiano emprende un rápido repaso del largo proceso de nuestra tradición literaria con el fin no solo de dilucidar el "horizonte histórico del que surgió [el boom] y dentro del cual es cabalmente comprensible" (98), sino de poner en tela de juicio este "club heterogéneo que sus apologetas presentaron como una flor silvestre" y de cuyas interpretaciones desaparecieron "las más elementales referencias históricas" (91).

Para Gutiérrez Girardot fueron sus precursores inmediatos -Leopoldo Marechal, Eduardo Mallea, Agustín Yánez o Juan Carlos Onetti, entre otros-, quienes "sin proponérselo, pusieron de presente con su obra la insuficiencia literaria y la estrechez humana" del indigenismo. Aleccionadora insuficiencia, pues como escribe a reglón seguido, "el indigenismo, su fracaso y sus superadores constituyen el subsuelo histórico y, para decirlo con una frase de Kant, la condición de posibilidad del llamado boom" (91). Más adelante, en relación con el problema de las influencias recibidas, árbol genealógico en el que destaca la figura de William Faulkner, decisivo en las obras de Gabriel García Márquez y Juan Carlos Onetti, apunta la necesidad de la existencia previa (sin la cual no hay asimilación posible), de una situación que posibilitara dicha receptibilidad y que, entre otros, crearon “Alfonso Reyes, Pedro Henríquez Ureña, el inspirador de los dos, esto es, José Enrique Rodó, Rubén Darío y más inmediatamente Eduardo Mallea y lo que representó -horrible dictu- la revista Sur" (91). Su conclusión se convierte en una explícita indicación del camino adecuado hacia una cabal comprensión de la historia literaria de nuestro continente, en otras palabras, hacia la plena comprensión de nuestra tradición y su papel en la conformación de nuestra conquistada originalidad. Escribe Gutiérrez Girardot:

La recepción de Faulkner por Onetti y por García Márquez, que aún esta por precisar, pesa menos que el largo proceso de la literatura hispanoamericana, iniciado por Andrés Bello y Domingo Faustino Sarmiento en el siglo pasado, planificado por José Martí y Rubén Darío y ya en la aurora del siglo presente por José Enrique Rodó, y que por encima de las vanas disputas entre los "hispanistas" como José de la Riva Agüero y los "indigenistas”, continuó en Alfonso Reyes y Pedro Henríquez Ureña, en Mariano Picón Salas y Eduardo Mallea, en Jorge Luis Borges y Agustín Yánez, entre otros más (Q46-47: 92). 
Esta ilustre genealogía no deja lugar a dudas sobre el análogo propósito "bolivariano y martiano" que anima una concepción historiográfica empeñada en rescatar, a través de la adecuada contextualización de un fenómeno como el boom, la figura de su admirado Pedro Henríquez Ureña y la tradición que representa. A diferencia de la antología Hispanoamérica: imágenes y perspectivas (1989), donde apareció por primera vez bajo el título “América sin realismos mágicos”, la antología Insistencias (1998), utilizó su título completo, "Los olvidados: América sin realismos mágicos". Porque esto sigue siendo: una lúcida y exigente reivindicación de un hombre tan olvidado como la tradición que lo hizo posible.

En esta misma línea de cuestionamiento a aquellos lugares comunes cuya fácil aplicación depara el placer de reducir la complejidad de las obras literarias a "juguetonas etiquetas", se encuentra el artículo titulado “¿Sólo un problema de historiografía literaria?” (Q171), incluido en el "Dossier: otro 98" (Rafael Gutiérrez Girardot, Eduardo Subirats, Enrico Mario Santí). Como su título lo sugiere, se trata de una aguda crítica al concepto de "generación", para el cual la historiografía literaria española no estuvo en condiciones de preguntarse por la validez científica de una "teoría" que fue "el zócalo sobre el que se edificó el monumento nacional de la "Generación del 98" y que hoy irradia, todavía, como medida canónica de la historia literaria española" (25). Cuestión de "rótulos, de losas sepulcrales", este concepto conforma un "mausoleo nacional" que no solo reduce considerablemente el "horizonte histórico-literario e histórico-social de la época", sino que imposibilita el examen adecuado de lo que "significó precisamente el 98, no sólo en España sino en el mundo occidental” (27). Contextualizado por Gutiérrez Girardot en el mismo horizonte histórico de los complejos fenómenos sociales y políticos, religiosos y culturales que determinarían la "unificación del mundo" (Hobsbawn) iniciada en 1848, el grupo del 98 deja de ser una mera "expresión del Estado nacional cuya plenitud se revelaba en cumbres literarias" (Menéndez Pelayo) para convertirse en "un capítulo de la ambigüedad que caracteriza esta época del mundo occidental" (28).

Vayamos al segundo capítulo de Aproximaciones, "Dos teóricos de la sociología literaria", integrado por tres artículos: "Lukács revisited", "Walter Benjamin. Posibilidad y realidad de una filosofía poética” (1965), publicado originalmente en la revista madrileña Ínsula y "Walter Benjamin y sus afinidades electivas" (Q9-10), aparecido en 1981. Es probable que aquel ensayo de 1965 sea uno de los primeros acercamientos al pensador alemán publicados en España ${ }^{8}$. El juicio es temerario (la recepción de Benjamin en España está por estudiarse). Bástenos considerar la carta del filósofo José Luis Aranguren, quien a pesar de su sólida formación filosófica pudo escribir a Gutiérrez Girardot: "De Walter Benjamin, por el que me pregunta, sólo conozco una interesante antología de

8 También en Colombia. Con el título: "Presentación de Walter Benjamin", fue incluido en El fin de la filosofía y otros ensayos (1986), primera antología de Gutiérrez Girardot. Y eso fue: una presentación del autor alemán en el ámbito cultural colombiano. 
cartas, que por cierto me regaló un joven amigo alemán, traductor de algunas cosas mías" (Madrid, 14.8.65) ${ }^{9}$.

Como ya anotamos, la atención de Gutiérrez Girardot por la sociología comienza durante sus años de formación en España. Posteriormente, en Alemania, la lectura directa de autores como Marx, Adorno, Mannheim, Marcuse, Lucien Goldman, Georg Lukács o Walter Benjamin, entre otros, enriquece su comprensión de las complejas relaciones entre literatura y sociedad, formuladas en una serie de trabajos aparecidos en los años sesenta y setenta, que se constituyen en los primeros pasos dados en el ámbito de los países de lengua española -junto a los de Ángel Rama o Noé Jitrik, entre otros-, encaminados a la formulación de los fundamentos teóricos necesarios para abordar una crítica social de nuestra literatura que estuviera a la altura de los desarrollos alcanzados en Europa.

Que el propósito de estos ensayos era novedoso e implícitamente "pedagógico" -en especial la señalada difusión de Walter Benjamin- lo demuestran las tempranas reacciones generadas, a ambos lados del Atlántico, luego de la publicación en Cuadernos hispanoamericanos del artículo "Literatura y sociedad en Hispanoamérica" (1968). No habían transcurrido dos meses, cuando José Ángel Valente escribe a Gutiérrez Girardot: "Querido Rafael: Qué bien tu ensayo. [...] Por cierto -lo digo por la extensa cita a pie de página- he comprado ahora una breve colección de ensayos de Benjamin publicada por Sur. Es lo primero de él que veo en castellano. No está entre ellos -y es lástima- $L a$ obra de arte en el tiempo de sus técnicas de reproducción" (Ginebra, 14.11.68).

La segunda reacción provino de José Luis Romero (1909-1977), más significativa aún si consideramos que se trata de uno de los historiadores más sólidos de Latinoamérica. Por las cartas que poseemos del historiador argentino, escritas entre 1966 y 1974, sabemos que el tema de las relaciones entre literatura y sociedad era frecuente entre ellos, si bien aún faltaban algunos años para que el historiador argentino publicara su obra fundamental, Latinoamérica, las ciudades y las ideas (1976). Poco antes de conocer su artículo, Romero escribe a Gutiérrez Girardot: "Su tema de la sociología de la novela me seduce mucho, porque estoy apasionado con el problema de la novela urbana" (Adrogué, 12.12.68). Cuatro meses más tarde, escribe de nuevo, esta vez agradeciendo el envío:

Mi querido Rafael: [...] Recibí su folleto sobre "Literatura y sociedad". Me entusiasmó. El enfoque es preciso y justo, sin excesos sociologizantes ni caídas esteticistas, que creo que es lo que se necesita para entender esta relación. Está lleno de observaciones felices y agudísimas, que no suelen verse en estudios sobre la literatura

9 Hasta donde sabemos, las dos primeras traducciones de Benjamin al español datan de 1967: Héctor A. Murena. Ensayos escogidos. Buenos Aires: Sur (creemos que se trata de la "breve colección" de ensayos mencionada más adelante por José Ángel Valente a Gutiérrez Girardot, en una carta fechada en 1968) y Rincón, Carlos. "Destino y carácter". Eco. Revista cultural colombiana. En 1970 apareció una tercera: Roberto J. Vernengo. Sobre el programa de la filosofia futura y otros ensayos. Caracas: Monte Ávila. En España, las primeras traducciones (Jesús Aguirre) aparecen en la editorial Taurus: Iluminaciones I. Imaginación y sociedad (1971) e Iluminaciones II. Poesía y capitalismo (1972). 
hispanoamericana. Pero lo que más me interesa es la metodología: creo que Ud. está -quizá sin proponérselo mucho-en el buen camino (Adrogué, 10.4.69).

Escrito casi dos décadas después, en 1981, el ensayo "Walter Benjamin y sus afinidades electivas" (Q9-10), sigue animado por aquella intención divulgadora del gran pensador alemán que iniciara en el ámbito de lengua española el citado artículo "Walter Benjamin. Posibilidad y realidad de una filosofía poética" (1965). Como declara en la "Advertencia" de Aproximaciones, en su momento ambos trabajos trataron de "poner de presente los problemas que caracterizan a la consideración marxista-leninista de la literatura, que en Hispanoamérica y en España se ha tomado como dogma" (8). Esta distancia temporal nos permite vislumbrar la modalidad reiterativa que caracteriza el acercamiento de Gutiérrez Girardot a sus objetos de estudio, pues como él mismo declara, "la insistencia misma es una aproximación". De estas insistencias en torno a Benjamin, digamos solamente que "no es la orientación política inmediata, sea de izquierda o sea conservadora" lo que interesa a Gutiérrez Girardot, sino "la variedad de los enfoques para captar la variedad de la realidad literaria" que Benjamin investiga, en otras palabras, el interés por divulgar una obra cuyo pensamiento venía a significar "una interrogación y un cuestionamiento [...] al dogma burocrático, tan pertinaz en muchos críticos de los países de lengua española" (Aproximaciones 8). De este modo, mientras en el artículo de 1965 intenta una "difusión menos snob, una asimilación profunda de sus ideas", esto es, la comprensión de la unidad cognoscitiva de una obra que a través de la ruptura de los vínculos entre filosofía y poesía o creación literaria se constituye para Gutiérrez Girardot "en el último apoyo del intelecto en la época del nihilismo y el primer intento de expresión del futuro" ("Walter Benjamin. Posibilidad y realidad" 13), el artículo de Quimera (1981) aborda la compleja relación del pensador alemán con la tradición alemana, esto es, con algunas de sus "afinidades electivas". Liberado de los dogmatismos de la izquierda del 68, de las "parcialidades de Adorno" y de quienes hicieron de él un prestigioso autor solo para "iniciados", lo cierto es que Benjamin sigue presentando problemas de difícil solución, principalmente, el problema de la "tradición de un revolucionario" (Q9-10: 23). Nutrido por las ambigüedades propias del intelectual "burgués" -que en general nutrieron la inteligencia crítica y revolucionaria desde la Ilustración y desde "uno de sus herederos", Marx-, las afinidades de Benjamin con Carl Schmitt (quien se prestó a justificar el régimen de Hitler con la frase: "el Führer hace el derecho") o con Max Kommerell (quien como Benjamin, se movía "en un terreno limítrofe entre ciencia y literatura"), no son para Gutiérrez Girardot solo contradicciones. Son el resultado de una situación histórica que Bloch caracterizaría como "simultaneidad de lo no simultáneo" (27), confluencia de lo contemporáneo y de lo anacrónico, esto es, la situación misma de la modernidad, horizonte que posibilita la aparición de aquellas "inteligencias libremente oscilantes" (28), como las define Karl Mannheim, de las que surgiría una figura de la vida política y social de "ambiguo y contradictorio perfil": "el francotirador, más precisamente el guerrillero intelectual, que habría de sustituir al bohemio decimonónico", aquel que "en un mundo que tiende a la uniformidad [...] se sustrae a su remolino y exige autonomía frente a la tendencia niveladora y a la vez busca el contacto revolucionario con el proceso planetario" (28-29). Palabras que Gutiérrez Girardot hará suyas, añadimos nosotros, el 
estímulo del ethos polémico que caracteriza su trabajo intelectual, la lección de rigor y libertad promulgada por el ensayista colombiano.

El ensayo titulado “Georg Büchner: entre el dandismo y la revolución” (Q15), comparte con el anterior texto de Benjamin el interés de nuestro ensayista por aquellos escritores y pensadores cuyos aportes han contribuido a perfilar las complejas ambigüedades que configuran el horizonte de la modernidad ${ }^{10}$. Y si bien no se trata de descubrir posibles o reales influencias - toda vez que la obra de Büchner (1813-1837) pasó casi desapercibida hasta comienzos del siglo XX-, no deja de anotar el "parentesco" que hay entre su trabajo y el pensamiento de Nietzsche, Gottfried Benn, o el procedimiento de que se servirían Hermann Broch y Robert Musil para darle "transparencia y hacer perceptible por medio del lenguaje el estado de disolución y el nihilismo contemporáneos" (15). En pleno período romántico, los dramas de Büchner concentran “en forma de símbolos toda la situación histórica de la Europa decimonónica”, al tiempo que permiten vislumbrar "sus consecuencias universales en el siglo presente". Se trata para Gutiérrez Girardot de uno de los primeros europeos en padecer aquellas oscilaciones que, como lo indica el título del ensayo, se mueven entre el "dandismo" y la "revolución", es decir, entre el "cansado aburrimiento y la apatía cínica" expresados en La muerte de Danton (1835) -“síntomas - para Hegel- de una época en período de transición [...] que se desmorona y que va presintiendo en esos síntomas la proximidad de algo desconocido" (Q15: 15) - y una "acción revolucionaria" que es "optimismo y fe en la libertad racional del hombre". Oscilación de una tensión histórica en la que el dandismo, que cobija a toda la literatura moderna, es el síntoma de que "algo nuevo y desconocido se anuncia, de que lo establecido, sometido también al fatalismo de la historia, se va resquebrajando hasta su definitiva disolución" (17). Este "aniquilante" fatalismo, que aparece en Büchner como la aguda conciencia de que el hombre ha dejado de ser el dueño de sí mismo, de que "nadie, pese a su aparente libertad, puede escapar a lo que ya se ha decidido", puede

${ }^{10}$ En esta misma dirección pueden considerarse los artículos "Jakob van Hoddis o la nobleza desafiante de la Bohemia" (Q147) y "Ernst Stadler o las ambigüedades de la vanguardia" (Q224/225). Al igual que contribuyó a la introducción de Benjamin en España, el artículo de Büchner publicado por Gutiérrez Girardot en Quimera en 1982 (Q15), se constituye en una de las primeras contribuciones a la "reintroducción" del dramaturgo alemán en el ámbito español. El artículo permitiría "enterrar la proyección esquemática de lugares comunes" acerca del autor y su época, y sustituir el debate biografista y el desengaño como fuente de creación por uno más sugerente: el de la ambigüedad existente "entre la razón escéptica y la pasión revolucionaria". Pero Gutiérrez Girardot sería también "el introductor de la narrativa -esto es, del relato Lenz- de Büchner en España [...] El profesor de la Universidad de Bonn logró una cuidada versión [...] que se publicó acompañada con la novedad para los estudios literarios españoles de una introducción a la figura del Lenz histórico, de forma que se explotaba plenamente la singular ocasión de documentación de la perspectiva lectora" (Javier Orduña. "Introducción". Georg Büchner. La muerte de Danton, Woyzeck. Introd., trad. y notas Javier Orduña. Madrid: Cátedra, 1993, p. 78). Para la citada versión: Lenz. Trad., pról. y notas Rafael Gutiérrez Girardot. Barcelona: Montesinos, 1981. 
equipararse a la noción de "progreso" elaborada por Benjamin a partir del cuadro de Paul Klee, “Angelus novus", alegórico ángel de la historia en el momento de volver su rostro al pasado, y que allí, donde a nosotros solo nos es dado ver "una cadena de acontecimientos", el ángel ve "una sola catástrofe que incesantemente amontona escombros sobre escombros [...] Bien quisiera detenerse, despertar a los muertos y juntar lo destrozado", pero desde el Paraíso una tormenta "lo empuja inconteniblemente hacia el futuro al que él vuelve las espaldas mientras el montón de escombros frente a él crece hasta el cielo. Lo que llamamos progreso es esta tormenta" (Q9-10: 29).

Tercero y último de los ensayos incluidos en Aproximaciones, "La lucidez histórica de Jorge Guillén" (Q37) es el esbozo de otro de los problemas implícitos en "El Modernismo incógnito": nos referimos al "fatigante problema de la función de la literatura en la sociedad y el de la llamada "élite" intelectual". Desde este punto de vista -esto es, del de los defensores de quienes exigen el "compromiso" del intelectual o el poeta con el pueblo-, la elección de dos poetas como Gottfried Benn y Jorge Guillén resulta una evidente provocación. Representantes de aquella élite, y por esto mismo considerados desde una perspectiva reduccionista y provinciana como poetas asociales por excelencia, la provocación se encamina al desenmascaramiento de una concepción "realista" de la literatura que tácitamente exige la renuncia a los procedimientos expresivos que esta ha configurado a lo largo de siglos de desarrollo en beneficio de una literatura de "casticismos" para ese pueblo que, como escribe con acertada ironía borgiana, pide del lector "más que conocimiento de la literatura y capacidad de pensar y de imaginar, familiaridad con la botánica y la zoología" (Aproximaciones 9).

Como otras aproximaciones a este complejo problema, el ensayo también se convierte en una implícita defensa de la autonomía de la creación poética, toda vez que "precisamente por esa libertad puede ella descubrir aspectos de la realidad histórica que quedan necesariamente ocultos a quienes versifican con una visión previa y fijada dogmáticamente de la realidad histórica" (9). El unitario propósito que articula la obra de Jorge Guillén hace de ésta una experiencia "única en la historia de la lírica occidental contemporánea -ni Saint-John Perse, ni E. Pound, ni T. S. Eliot, ni W. B. Yeats tienen igual sentido de la conciencia constructiva de la creación poética" (Q37: 25)-, constituyéndose para Gutiérrez Girardot en "el primer intento logrado en lengua española de dar a la poesía la densidad intelectual y la capacidad de penetración que caracterizó a la fenomenología de Husserl o al pensamiento de Heidegger, sin que por ello pierda su alto temple lírico" (27). La "lucidez histórica" del poeta Jorge Guillén, esto es, su capacidad de "penetrar lo inmediato y encontrar tras ello y en ello el horizonte histórico de la realidad" se transmuta en una voz "serena, transparente y afirmativa" que representa para Gutiérrez Girardot la mejor refutación a un populismo que confunde lo histórico con sonora retórica, al tiempo que pone en cuestión los frecuentes reproches hechos a la supuesta inhumanidad de su poesía $^{11}$. Estas acusaciones - pretextos del escritor para ocultar la mediocridad de un

11 Para Gutiérrez Girardot, "la afirmación de la vida, el cántico, la "fe de vida" de Jorge Guillén es comprensible como interpretación y respuesta de la situación histórica y espiritual 
parroquialismo disfrazado de "compromiso"- fueron las que junto con el indigenismo hispanoamericano, contribuyeron a que la poesía de lengua española "se sustrajera a la participación en el esclarecimiento de los problemas que implicaron la profunda crisis del pensamiento europeo" (26). Con más hondura y penetración que "el inmortal Pablo Neruda", Guillén supo penetrar en estos complejos problemas.

Una indagación similar sobre la lírica y su relación con la realidad histórica se encuentra en el artículo "Poesía del silencio" (Q191), escrito para el "Dossier: Paul Celan" (Rafael Gutiérrez Girardot, Alain Suied, Arnau Pons y Jean Bollack), dedicado por Quimera a los 80 años del nacimiento del gran poeta ucraniano (1920-1970). Situado en la coyuntura del silencio impuesto a la poesía luego de la Segunda Guerra Mundial -que llevaría a afirmar a Theodor W. Adorno en su Crítica de la cultura y sociedad (1949): "Escribir un poema después de Auschwitz es bárbaro"- la obra lírica de Paul Celan, "que por su hermetismo parece callar", aparece ante el ensayista colombiano como un desafío a los que callan. Signada por "el sello del silencio que impone la barbarie de la Europa que posibilitó Auschwitz" y por la búsqueda de un nuevo lenguaje que pueda nombrar todo aquello enmudecido después del Holocausto, su "cuestionamiento radical del arte" está presidido por una concepción del poema como un "estar en camino en busca de un tú y realidades asequibles", pero también por la necesidad de un "estar arraigado en el recuerdo" (eingedenk sein), que en alemán significa una reactualización de la memoria. Desde esta perspectiva, la de Celan es una "poesía comprometida" pero no en el sentido demagógico que tuvo este postulado: arraigada a su materia biográfica, sus contenidos dejan sin embargo su ámbito puramente individual para devenir representación de la "historia inmediata y de la historia remota del pueblo judío", que "como historia del pueblo elegido de Dios, es la historia de Occidente". El lector de la poesía de Celan no ha de ser un lector "ajeno a la historia": ha de poder percibir que todo poema tiene inscrito su "20 de enero" (25Q: 21) ${ }^{12}$.

de toda una época marcada por el positivismo y la creciente dominación de las ciencias naturales, es decir, por una racionalización empobrecedora y empobrecida de la vida, por un estrechamiento de sus horizontes, por el sometimiento de la riqueza de la vida al cálculo reductor" (Q37: 25).

${ }^{12}$ La fecha es una alusión de Celan al comienzo de la narración Lenz, de Georg Büchner: "E1 20 de enero Lenz caminaba por la sierra...", basada en el "poeta genial desamparado [...] que murió abandonado en una calle de Moscú" (Q191: 20). Escribe Celan en "El Meridiano" (discurso con motivo de la concesión del Premio Georg Büchner, 1960): “¿Se puede decir tal vez que en cada poema queda grabado su "20 de enero"? ¿Es tal vez la novedad de los poemas que se escriben hoy precisamente eso: que en ellos se intenta con toda claridad que esas fechas queden en el recuerdo? ¿Pero no procede nuestra escritura, la de todos, de tales fechas? ¿Y a qué fechas está signada nuestra escritura?" (Celan 2000: 505). Ya antes, en otro artículo publicado también en Quimera, titulado "Jakob Michael Reinhold Lenz o la inmortalidad del desamparo" (Q131-132: 68-79), Gutiérrez Girardot resumía la profunda vinculación de Celan con Büchner y Lenz: "El arte, el desamparo, el judío errante son los puntos de partida 
Muestra de la vocación del crítico colombiano por fomentar el diálogo entre nuestra literatura y la experiencia literaria europea, el ensayo convoca las figuras de Antonio Machado (1876-1939) y César Vallejo (1898-1936) para señalar cómo la "poesía del silencio" de Paul Celan se asemeja -en su búsqueda de realidad y orientación que lo llevaría a los "límites del lenguaje y de la comunicación, al silencio que lleva en sí la esperanza de abrir el camino a una utopía" (Q191: 25-26)-, a la poesía de Antonio Machado: "La poesía del silencio de Celan es palabra en el tiempo" (26). También a la voz del peruano, a través de las diversas suscitaciones abiertas por la pregunta de Hölderlin, “¿Para qué poetas en tiempo menesteroso?”: en su intento de "destrucción y reconstrucción de la lengua de los verdugos", en su "busca de un tú y de una realidad asequibles", Paul Celan configuró en su dialéctica poesía del silencio la experiencia de una "mudez expresiva" que para el ensayista colombiano no difiere de la que legó César Vallejo en su poema póstumo "Intensidad y altura":

Quiero escribir, pero me sale espuma,

Quiero decir muchísimo y me atollo;

no hay cifra hablada que no sea suma, no hay pirámide escrita sin cogollo.

\section{DOS PROVOCACIONES}

Escribe Gutiérrez Girardot en las palabras preliminares de esta antología: "Los ensayos reunidos en este volumen pretenden solamente proponer lo que es habitual en la vida intelectual del resto del mundo: discusión fundada, crítica, juicio libre, exclusión de mitos, es decir, cuestionamiento de toda simulación" (Provocaciones 12). Más allá de esta declaración de propósitos, más allá de su fundamentado y cabal cumplimiento, los diez ensayos reunidos en Provocaciones se constituyen en una muestra ejemplar de una de las características más destacadas de su estilo ensayístico: la actitud polémica y peleadora que sustenta su obra: ya dirigidos contra el famoso romanista Ernst Robert Curtius, cuyo método de trabajo, "la acumulación erudita y la carencia de sentido de problemas, sigue siendo el "método" habitual de las investigaciones -si así cabe decir- sobre las letras de lengua española" (10); ya contra las especulativas nebulosidades y ocurrencias del "filósofo, helenista, sociólogo, germanista, anglista, galorromanista, hispanista, orientalista y místico mexicano Octavio Paz" (15); ya contra el falso y anacrónico problema de la "identidad hispanoamericana", entre otros ${ }^{13}$,

de Paul Celan en su interpretación y asimilación de Büchner-Lenz" (78). Ellos “constituyen el trasfondo histórico-literario y personal de la poética del silencio de Celan" (79).

13 Tres polémicas de Gutiérrez Girardot aparecieron en Quimera: 1) "Dos veces humor" (Q14), con el escritor colombiano Ricardo Cano Gaviria. 2) "Machado polémico" (Q45), con Juan Goytisolo, precedida por esta aclaración: "En el No 43 de Quimera se publicó el artículo de Juan Goytisolo, "Modernidad y dogmatismo: Jdanov, Joyce y Machado", al 
estos implacables cuestionamientos encuentran en la figura de Ortega y Gasset su más paradigmática manifestación. Todos ellos, sin embargo, pueden leerse como expresión de aquella tercera "praxis de mi guerra" expuesta por Nietzsche en Ecce homo (1903), que Gutiérrez Girardot utiliza para delinear, en su ensayo "Karl Kraus y el lenguaje como sátira" (Q160) ${ }^{14}$, la actitud del genial escritor alemán y que bien puede aplicarse a nuestro ensayista:

Tercero: nunca ataco personas, -me sirvo de la persona sólo como de un fuerte lente de aumento con el que puede hacerse visible una situación crítica general. Como Nietzsche [como el propio Gutiérrez Girardot, repetimos], Kraus atacó vanidades triunfantes, las atacó a corps perdue, solo, sin acudir a nadie que lo secunde en ese ataque, atacó a personas (los periodistas y escritores triunfantes) como síntomas de una situación general crítica [...] y tuvo conciencia de que ese ataque era un acto de benevolencia (40).

De benevolencia, o de amor, porque la sátira, esa otra forma del desenmascaramiento y la provocación, "mantiene unido al satírico con los objetos de su ataque, es decir, la sátira es acto de caridad porque el lenguaje es lazo de unión con los que han pervertido el lenguaje" (40).

Ejemplar ilustración de este lazo de unión fue la larga y peleadora relación que Gutiérrez Girardot mantuvo con Ortega durante casi cuatro décadas, desde 1948 -cuando el joven estudiante (20 años) publica su primer artículo, una entusiasta apología de la razón vital titulada "José Ortega y Gasset", evidencia de la honda influencia ejercida por el pensador español en el ámbito hispanoamericano- ${ }^{15}$, hasta sus agudas e implacables denuncias por la introducción en el ámbito del pensamiento en lengua española de un "estilo de trabajo" fundamentado - como reza el título de uno de sus ensayos-, en el "arte de la simulación majestuosa" (1981). Una última confrontación, el artículo "José Ortega y Gasset y Xavier Zubiri” (1986), pondrá el dedo en la llaga al evocar el magisterio de Zubiri, lección de disciplina intelectual que habrá de significar, para

que, si bien compartiendo la "justa crítica al juicio deformador con que se castiga a Antonio Machado", el profesor Rafael Gutiérrez Girardot hace ahora algunas precisiones". 3 ) "Sobre la hispanística" (Q152), publicada con esta presentación: "En oposición a los artículos que hasta la fecha han ido nutriendo el debate que en Quimera se ha llevado a cabo en torno a la hispanística, Gutiérrez Girardot se distancia en este polémico y esclarecedor artículo tanto del rancio positivismo como de las teorías de la literatura en boga" (44).

${ }^{14}$ Incluido en el Dossier: "Karl Kraus", compuesto por trabajos de: Gerald Krieghofer, Jordi Ibáñez, Adam Hovacsis, Rafael Gutiérrez Girardot, Theodor Haecker, Bernd Marizzi, Ernst Krenek, Antonio Ribeiro y la traducción del texto "Hitler", de Karl Kraus.

15 "No se negará, ni se puede desconocer el hecho de que Ortega dominó más de medio siglo de la cultura de lengua española y que gracias a su obra como editor y como suscitador de traducciones de obras modernas de la filosofía alemana [a través de la editorial y de la Revista de Occidente], contribuyó esencialmente a que los hispanos no continuaran su terco proceso de embrutecimiento entregados a los tomismos domésticos” (Q103-104: 74). 
quienes aprendan del olvidado maestro, "lo que [solo] postulaba Ortega: radicalidad en la pregunta, detalle en la investigación, exactitud en el planteamiento del problema, precisión y nitidez en el desarrollo del mismo, y formación del concepto que además de claro debe ser internamente necesario" ("José Ortega" 13). Alumno de Zubiri durante su período de formación en Madrid, Gutiérrez Girardot dejará en Quimera un justo y sentido homenaje con motivo del fallecimiento (1983) de "Xavier Zubiri”: "El ejemplo de sus cursos consistió no en la formulación de teorías sino [...] esencialmente en los cambios que abrió y en el procedimiento para desbrozarlos: en la forma radical de preguntar, lo que a su vez significa la manera de poner las doxas en tela de juicio, de despejar de dogmas el trecho que ha de recorrer el pensamiento para llegar "puramente" a sus objetos" (Q33: 4).

De los tres ensayos sobre Ortega incluidos en Provocaciones, dos están específicamente dedicados a éste: "José Ortega y Gasset. En el primer centenario de su nacimiento" (1983) y "Ortega y Gasset o el arte de la simulación majestuosa" (Q103104). El tercero, "Sobre la crítica y su carencia en las Españas" (Q24), si bien no gira específicamente en torno a Ortega, se relaciona íntimamente con él, pues si en beneficio de su acción como intelectual - esto es, en beneficio de la clarificación de su valor específico dentro del panorama del pensamiento español- se hace necesario destruir el mito de Ortega como gran filósofo - canonización que "impide una valoración adecuada de sus pretensiones y realizaciones" (para Gutiérrez Girardot el valor de su obra es "histórico y sociológico")-, también se hace necesario preguntar por las causas de la formación de ese mito, una de las cuales, la principal, es precisamente "la carencia de crítica en las Españas”. Ortega sucumbió a ella. Su pretendida renovación de la filosofía no supo, o no pudo, como anota en el "Preliminar" de Provocaciones,

asumir el rigor-el esfuerzo del concepto como lo llamó Hegel-que había determinado la filosofía que Ortega no sólo creyó introducir sino superar: la filosofía occidental. Esta discrepancia entre su pretensión y la realización de ella lo obligó no tanto a ser aristócrata (del pensamiento...) en la plaza vulgar, sino a ser un maestro en el arte de la "simulación majestuosa" (8-9).

Un mes antes de su publicación, Ángel Rama remite a Gutiérrez Girardot una carta en que manifiesta su positiva opinión sobre el texto y el temor de que la revista no lo publique: "La nota del innominado R.G.G. es de una ferocidad que da el mejor acento hispanoamericano de rebeldía, el válido orgullo de no aceptar que fijen los parámetros y además con ellos nos juzguen. Espero que pueda aparecer, pues encuentro a los amigos de la revista muy prudentes" (Washington, 1.9.82). El temor era una referencia a las contundentes y provocadoras afirmaciones de un ensayo que busca demostrar cómo el "complejo de inferioridad" y de envidia frente a Europa, expresados en 1913 por Ramiro de Maeztu en el prólogo de sus Ensayos (1948) -envidia que Unamuno llamaría el "mal nacional"-, fomentaron la ilusión de que "el gesto científico equivale a trabajo sistemático, de que la forma puede sustituir al contenido. De esta manera, la simulación se ha convertido en el elemento vital de la vida intelectual de las Españas", con una fatal consecuencia: en ese elemento vital "no cabe la crítica, sino el dogma" 
(Q24: 18). Dentro de este panorama, Ortega se constituye en "una culminación de la prevalencia del dogmatismo sobre la razón, sobre la crítica, sobre las formas elementales del pensamiento científico" (15).

Ahora bien, mientras Ángel Rama celebraba el tono combativo de este texto, Gonzalo Sobejano, en una carta remitida a Gutiérrez Girardot este mismo año, si bien encuentra oportunas sus apreciaciones, no duda en reprocharle lo que considera una evidente exageración:

Tu trabajo sobre la crítica en España, partiendo de Ortega, y deteniéndote en Bousoño, a mi parecer era necesario. Cabe que se te haya ido un poco la mano en la mostración de lo mala que ha sido la crítica española y sobre todo en que Ortega tenga gran culpa en ello; podría haber sido Ortega un desorientador [...] Sin embargo, en último término, tu mostración era conveniente, diría higiénica (s/c, 31.12.82).

Reproche que deja al descubierto, debemos añadir, el que quizá sea uno de los aspectos más débiles y, en ocasiones, inconsistentes del trabajo intelectual de Gutiérrez Girardot: no la saludable actitud polémica contenida en un ejercicio crítico altamente exigente, tan "higiénico" como necesario para el ámbito de nuestro pensamiento -que él mismo denomina "pedagogía literaria"- ${ }^{16}$, sino sus habituales excesos: la inútil reiteración de sus irónicas burlas, la desmedida urgencia por aniquilar con insultos sus objetos de desaprobación, ese ensañarse con enemigos ciertamente ya derribados, debilitando con estos procedimientos la certeza de sus argumentos. Si bien es cierto que, también hay que decirlo, dichos excesos parecen encontrar "justificación" si los consideramos a la luz del género que hizo suyo y dentro del cual fue indiscutido maestro: el ensayo. Modalidad que su maestro Hugo Friedrich define con precisión en su Montaigne (1949): "En cuanto es una configuración entre prosa y poesía está [el ensayo] abierto tanto a la reflexión como a la intuición, tanto a los intereses objetivos como a los simples humores" (Gutiérrez, En torno 37).

Un año antes de aparecer su artículo "Sobre la crítica y su carencia en las Españas" (1982), otro ensayo dedicado al pensador español, "Ortega y Gasset o el arte de la simulación majestuosa" (Q103-104), ya acometía la "higiénica" labor señalada por Sobejano. Publicado originalmente en El viejo topo (1981), volvía a circular en España diez años después, en un número homenaje de Quimera (1991) dedicado a rescatar, como declara su página editorial, "algunos de los mejores artículos aparecidos en el Topo" ("El viejo”, Riera 3), evocación que nos permite percibir la decidida actitud de los intelectuales

16 "Pero crítica, sátira y polémica están tan cerca la una de la otra, que sólo se pueden ver sus límites en cuanto se las contempla desde su origen: el portador común sobre el que descansa todo el edifico del conocimiento y del lenguaje (Fr. Schlegel) [...] más todas ellas se alimentan del deseo de purificar el lenguaje, que es purificar el mundo. Todas ellas se alimentan de una mística de la palabra y son, como en Kommerell el ensayo, una pedagogía literaria" (Gutiérrez, En torno 43). 
catalanes en los primeros años del posfranquismo, al tiempo que refleja la análoga actitud combativa que orienta los trabajos del crítico colombiano. Escribe Riera:

Muchos, pienso, añoramos aquella publicación. No exactamente sus contenidos, rebasados por una historia que cada vez en más veloz, sino su talante abierto, crítico y, sobre todo, radical. Su voluntad de afrontar todos los tabús, de desoír todas las prohibiciones. Su interés en evitar la sacralización de la palabra [...], en reclamar de cada uno de nosotros esa cosa tan difícil que es intentar pensar por nosotros mismos (3).

Basten estas anotaciones al margen para incitar la lectura de una aproximación crítica que si por un lado denuncia con provocadores ejemplos el "estilo de trabajo" de Ortega -"intimidar" con relaciones que nunca tuvo (mi "maestro Cohen", "mi gran amigo Scheler"); proclamarse un adelantado; presentar trabajos "brillantes, pero no adecuadamente desarrollados"; prometer trabajos que nunca escribiría-, por el otro resume plásticamente las negativas consecuencias que dejó en Hispanoamérica su desmedida influencia:

El Don Juan filosófico en potencia que fue Ortega, nunca se atrevió al acto donjuanesco. Recomendaba, pero no hacía lo que recomendaba. Hablaba innecesariamente de "rigor" y de "rigoroso" (hispanización innecesaria y pedantesca del alemán rigoros), y para serlo, se bastaba con decirlo. Los vicios que Ortega consagró, pesaron infinitamente más que las suscitaciones que le hicieron famoso (16Q: 73-74).

Luego de los legítimos reproches dirigidos a Gutiérrez Girardot por Gonzalo Sobejano, el hispanista español aventura un pronóstico sobre su recepción en España: "Estate seguro: te lo afearán o condenarán los más; los mejores pensarán que hiciste bien, y no pensarán así por celos o envidias de capilla (me atrevo a suponerlo), sino porque verán que había, que hay justicia en lo dicho" (s/c, 31.12.82). Al final de la citada carta, escribe a su amigo: "Cuando veo tu activa y militante -juvenil- colaboración en Quimera me entra un complejo de esterilidad e infecundidad", íntima confesión que si por un lado denuncia las demandas de su trabajo universitario: "tengo todo el tiempo impedido y nada puedo mandar a Quimera", por el otro deja implícitamente señalado el aporte esencial de una obra cargada de fructíferos llamados y cuestionamientos. Porque eso fue el trabajo de Rafael Gutiérrez Girardot: una vigorosa incitación al trabajo constante, una incansable invitación a poner en tela de juicio las trampas del facilismo y la simulación, un reflexivo recordatorio de la perpetua juventud de nuestra vieja, olvidada tradición.

\section{BIBLIOGRAFÍA}

Borges, Jorge Luis. “El escrito argentino y la tradición”. Obras completas. Tomo I. Barcelona: Emecé, 1989. 267-274.

Celan, Paul. Obras completas. Madrid: Trotta, 2000.

Gutiérrez Girardot, Rafael. "La utopía americana de Alfonso Reyes". Cuadernos Hispanoamericanos 25 (1952): 73-82. 
La imagen de América en Alfonso Reyes. Madrid: Ínsula, 1955. En torno a la literatura alemana actual. Barcelona: Taurus, 1959.

"Walter Benjamin. Posibilidad y realidad de una filosofía poética". Ínsula 221 (1965): 13 .

"Literatura y sociedad en Hispanoamérica". Cuadernos hispanoamericanos 224225 (1968): 579-594.

"Respuestas a la encuesta de Gaceta de Colcultura". Gaceta 24 (1979): 7-9. “José Ortega y Gasset y Xavier Zubiri”. Aleph 57 (1986): 7-13.

"El desmitificador de lo telúrico”. Entrevista. El Heraldo. Revista Dominical (27 dic. 1987): 3-7.

"Prólogo". Alfonso Reyes. Ultima Tule y otros ensayos. Selec. y Pról. Rafael Gutiérrez Girardot. Caracas: Biblioteca Ayacucho, 1991. IX-XLIII.

Mainer, José Carlos. Falange y literatura. Barcelona: Labor, 1971.

Reyes, Alfonso. "Notas sobre la inteligencia americana". Alfonso Reyes. Ultima Tule y otros ensayos. Selec. y pról. Rafael Gutiérrez Girardot. Caracas: Biblioteca Ayacucho, 1991. 230-235.

Riera, Miguel. "El viejo topo asoma el hocico". Quimera 103-104 (1991): 3.

“Quimeras. Entrevista a Miguel Riera”. Quimera 197 (2000): 9-15.

\section{ANEXO 1: Rafael Gutiérrez Girardot en Quimera (listado cronológico)}

Se incluyen las dos publicaciones de "Georg Büchner: entre el dandismo y la revolución" (1982 y 2001): la distancia cronológica lo justifica. Exceptuando este artículo -Razón y fábula 3 (1967): 22-29- y "Ortega y Gasset o el arte de la simulación majestuosa" -El viejo topo 54 (1981): 28-32-, los demás ensayos aparecieron por primera vez en Quimera. Por obvias razones, solo incluimos: "Título del artículo". Ejemplar (año): páginas.

1. "El rodaballo y la identidad perdida". 5 (1981): 46-49.

2. "Walter Benjamin y sus afinidades electivas". 9-10 (1981): 23-29.

3. “Dos veces humor". 14 (1981): 67-70.

4. “Georg Büchner: entre el dandismo y la revolución”. 15 (1982): 12-17.

5. “Una comedia de errores". 17 (1982): 24-25.

6. “Sobre la crítica y su carencia en las Españas”. 24 (1982): 12-21.

7. “El modernismo incógnito". 27 (1983): 8-11.

8. “Xavier Zubiri”. 33 (1983): 4-5.

9. "Noticia sobre Paul Celan". 33 (1983): 30-36.

10. “La lucidez histórica de Jorge Guillén”. 37 (1984): 25-27.

11. "Machado polémico". 45 (1985): 62-63.

12. "Los olvidados: América sin realismos mágicos". 46-47 (1985): 91-99. 
13. "Heidegger, a los 10 años de su muerte". 60 (1987): 43-49.

14. "El arte de la excepción”. 64 (1987): 61-65.

15. "El lento, lento vuelo de la alondra ensangrentada". 83 (1988): 30-35.

16. “Ortega y Gasset o el arte de la simulación majestuosa”. 103-104 (1991): 68-75.

17. "Pierre Ménard o Paul Mallarmé". 105 (1991): 54-61.

18. "Georg Christopher Lichtenberg o la modestia corrosiva". 125-126 (1994): 38-46.

19. “Jakob M. Reinhold Lenz o la inmortalidad del desamparo". 131-132 (1995): 68-79.

20. "La herejía de Günther Grass". 140-141 (1995): 72-75.

21. "Jakob van Hoddis o la nobleza desafiante de la bohemia". 147 (1996): 47-54.

22. "Sobre la hispanística". 152 (1996): 44-47.

23. "Karl Kraus y el lenguaje como sátira”. Dossier: "Karl Kraus”. 160 (1997): 34-40.

24. “SŚlo un problema de historiografía literaria?”. Dossier: “Otro 98”. 171 (1998): 2532.

25. "Poesía del silencio". Dossier: "Paul Celan". 191 (2000): 18-26.

26. “Georg Büchner: entre el dandismo y la revolución”. 207-208 (2001): 211-219.

27. "Borges y la Filosofía". 209 (2001): 36-45.

28. "Ernst Stadler o las ambigüedades de la vanguardia”. 224-225 (2003): 77-85.

ANEXO 2: Antologías de Rafael Gutiérrez Girardot

Listado cronológico de las ocho antologías donde fueron publicados los diecisiete artículos extraídos de Quimera (la numeración de los artículos corresponde al Anexo 1). Entre paréntesis, las antologías donde algunos ensayos aparecieron publicados por segunda vez.

\section{Aproximaciones. Bogotá: Procultura, 1986}

2. "Walter Benjamín y sus afinidades electivas" (III)

7. "El Modernismo incógnito" (VIII)

10. "La lucidez histórica de Jorge Guillén" (III)

II. Hispanoamérica: imágenes y perspectivas. Bogotá: Temis, 1989

6. "Sobre la crítica y su carencia en las Españas" (IV)

12. "Los olvidados: América sin realismos mágicos" (V)

\section{Cuestiones. México: FCE, 1994}

2. "Walter Benjamín y sus afinidades electivas"

10. "La lucidez histórica de Jorge Guillén"

15. "El lento, lento vuelo de la alondra ensangrentada"

17. "Pierre Ménard o Paul Mallarmé"

4. "Georg Büchner: entre el dandismo y la revolución" 
IV. Provocaciones. Bogotá: Ariel, 1997

6. "Sobre la crítica y su carencia en las Españas"

16. "Ortega y Gasset o el arte de la simulación majestuosa"

V. Insistencias. Bogotá: Ariel, 1998

12. "Los olvidados: América sin realismos mágicos"

23. "Karl Kraus y el lenguaje como sátira"

VI. Entre la Ilustración y el expresionismo: figuras de la literatura alemana. Bogotá: FCE, 2004

18. "Georg Christopher Lichtenberg o la modestia corrosiva"

19. "Jakob Michael Reinhold Lenz o la inmortalidad del desamparo"

21. "Jakob van Hoddis o la nobleza desafiante de la Bohemia"

25. "La mudez expresiva de la poesía de Paul Celan" [titulo original: "Poesía del silencio"]

28. "Ernst Stadler o las ambigüedades de la vanguardia"

VII. Tradición y Ruptura. Bogotá: Random House Mondadori, 2006

24. “Sólo un problema de historiografía literaria?”

27. "Borges y la Filosofía"

VIII. Pensamiento hispanoamericano. México: UNAM, 2006

7. "El Modernismo incógnito" 